\title{
Intestinal permeability and orocaecal transit time in elderly patients with Parkinson's disease
}

\author{
Keren N Davies, Debra King, David Billington, JA Barrett ·
}

\begin{abstract}
Summary
The aetiology of weight loss in patients with Parkinson's disease is likely to be multifactorial. We studied 15 patients with Parkinson's disease and 15 age- and sex-matched controls and looked for evidence of malabsorption due to small bowel bacterial overgrowth or alteration of intestinal permeability. There was a marked increase in orocaecal transit time in the patients with Parkinson's disease, although lactulose hydrogen breath testing did not show evidence of small bowel bacterial contamination. Intestinal permeability measured by the differential sugar absorption test was also deranged. There was reduced absorption of mannitol in patients with Parkinson's disease while lactulose absorption was similar in both groups, suggesting decreased non-mediated uptake across the enterocyte brush border membrane in patients with Parkinson's disease.
\end{abstract}

Keywords: intestinal permeability, sugar absorption, Parkinson's disease, bacterial overgrowth, nutrition, elderly

Weight loss is a frequent finding in elderly patients with Parkinson's disease, ${ }^{1-3}$ although the reasons have not been fully explained. An increase in energy expenditure has been shown in two studies ${ }^{1,2}$ whilst other possible contributing factors include dietary deficiency, ${ }^{3}$ or malabsorption due to small bowel bacterial overgrowth. ${ }^{4,5} \mathrm{We}$ have previously shown that dietary deficiency is unlikely to be the cause. ${ }^{6}$ In this study of elderly patients with Parkinson's disease who had lost weight we looked for evidence of malabsorption, due to either small bowel bacterial overgrowth or changes in intestinal permeability. The lactulose hydrogen breath test has been shown to be a reliable measure of small bowel bacterial overgrowth and orocaecal transit time. ${ }^{7-9} \mathrm{~A}$ differential sugar absorption test using mannitol and lactulose as probes was used to study intestinal permeability changes. ${ }^{10-12}$

\section{Methods}

Correspondence to Dr Keren Davies,

Department of Medicine for the Elderly, The Royal

London Hospital Mile End, Bancroft Rd, London E1 4DG, UK

\section{SUBJECTS}

Fifteen patients (nine women, median age 73.9 years, range 68.3-80.5) and 15 age- and sexmatched controls (median age 73.6 years, range 67.6-80.3) were studied. Ethical approval was obtained from the Wirral Health Authority ethics committee. All subjects gave written informed consent.

The patients had a definite diagnosis of Parkinson's disease and a favourable response to L-dopa therapy. None of the patients were taking anticholinergic medications. Their condition and medication had been stable for at least six months prior to study. Patients with co-existing chronic diseases, eg, diabetes, or with known gastrointestinal disease, were excluded. All controls were screened, healthy elderly people.

All subjects gave a full medical history, underwent physical examination and a lactulose hydrogen breath test. On a separate occasion at least one week later, the differential sugar absorption test was performed. Parkinson's disease was graded using the Hoehn and Yahr scale ${ }^{13}$ and the Nottingham activities of daily living (ADL) scale ${ }^{14}$ was completed for each patient. Disease duration and total daily dose of L-dopa was recorded for each patient.

\section{PROCEDURE}

\section{Lactulose hydrogen breath test}

Laxatives were discontinued for 48 hours prior to the procedure. All subjects were studied after an overnight fast having been asked to avoid foods likely to generate hydrogen for the 24 hours prior to the test. None had received antibiotics for at least two months and patients were asked to refrain from smoking on the morning of the test. Lactulose $(10 \mathrm{~g})$ was ingested with $50 \mathrm{ml}$ of water and end expiratory samples of breath analysed for hydrogen content before and at 5-minute intervals for 30 minutes and every 15 minutes for a further 150 minutes after. End expiratory breath was analysed using an EC60 electrochemical hydrogen sensor (Bedfont Sittingbourne, Kent). The test duration was 180 minutes. Orocaecal transit time was defined as the time between ingestion of the lactulose and the first definite and sustained rise in breath hydrogen. ${ }^{8,9}$ In practice, a rise of at least $5 \mathrm{ppm}$ above fasting levels in the end expiratory hydrogen concentration was taken as the transit time. An early rise in breath hydrogen followed by a fall and later rise signifies bacterial overgrowth in the small intestine. ${ }^{7-9}$
Differential sugar absorption test

A lactulose/mannitol differential sugar absorption test was performed. The amount of man- 
nitol recovered in urine in normal subjects is 40-100 times greater than the amount of lactulose recovered, as normal subjects absorb less than $1 \%$ of the lactulose administered. If intestinal permeability is abnormal there is an alteration in the amount of the sugars absorbed. Expressing the percentage urinary recovery of lactulose as a ratio of that of mannitol eliminates the effects of variability in absorption due to delayed gastric emptying or transit time through the intestine. Such effects would invalidate permeability tests using a single probe molecule. In addition, the differential sugar absoption test remains valid in the presence of renal impairment and does not depend on the accuracy of urine collection.

A sample of urine was collected after an overnight fast. Subjects swallowed a mixture of $5 \mathrm{~g}$ of lactulose, $2 \mathrm{~g}$ of mannitol and $22.3 \mathrm{~g}$ of glucose (as an osmotic filler) in $100 \mathrm{ml}$ of water. Urine was collected for the next five hours into a container to which $1 \mathrm{ml}$ of $20 \%(\mathrm{w} / \mathrm{v})$ chlorhexidine was added as preservative. The volume was recorded prior to storing a small sample $(10 \mathrm{ml})$ at $-20^{\circ} \mathrm{C}$ until analysis. Subjects fasted throughout the test but were allowed to drink up to $250 \mathrm{ml}$ of water two hours after ingestion of the sugars.

\section{Analytical methods}

Mannitol in urine was estimated as its trimethylsilyl derivative by gas liquid chromatography using alpha-methylglucose as internal standard. ${ }^{15}$ A Pye-Unicam gas chromatograph fitted with flame ionisation detectors and linked to a Pye-Unicam PU 4810 computing integrator was used. The column ( $2 \mathrm{~m}, 3 \mathrm{~mm}$ internal diameter) used was $10 \%$ OU17 or gas-chrom $Q$ and column conditions were as follows: oven temperature $190^{\circ} \mathrm{C}$, injector temperature $210^{\circ} \mathrm{C}$, detector temperature $350^{\circ} \mathrm{C}$, carrier gas (nitrogen) flow rate $40 \mathrm{ml} /$ min. Lactulose in urine was determined by enzymic hydrolysis to fructose and galactose by beta-galactosidase followed by detection of fructose by a NADP $^{+}$-linked spectrophotometric assay. ${ }^{16}$

\section{Statistical methods}

Data are described as median (range) percentage recoveries of each probe sugar in a five hour urine collection. Statistical analysis was performed with Mann-Whitney U test, Chisquare and Spearman's rank correlation $\left(r_{s}\right)$ where appropriate. A p-value of 0.05 was considered significant.

\section{Results}

The patients had a mean disease duration of six $(1-16)$ years and a mean daily dose of $L$-dopa of $450(150-1250) \mathrm{mg}$. There was a significant correlation between total daily dose of $\mathrm{L}$-dopa and disease duration $\left(r_{s}=0.59, p=0.01\right)$. Disease severity varied between Hoehn and Yahr grades 1 and 5 and the Nottingham ADL score between 3 and 10 . There was no significant correlation of Hoehn and Yahr grade with $\mathrm{ADL}$ score.

All of the Parkinson's disease patients and controls had plasma urea and creatinine levels within the normal laboratory limits. There was no correlation between the urea $\left(r_{s}=0.3\right.$, $\mathrm{p}=\mathrm{ns})$ or creatinine $\left(\mathrm{r}_{\mathrm{s}}=0.4, \mathrm{p}=\mathrm{ns}\right)$ and the percentage mannitol excretion.

Ten of the 15 patients with Parkinson's disease had orocaecal transit times greater than 180 minutes compared with three of 15 controls $\left(\mathrm{X}^{2}=4.89, \mathrm{p}=0.03\right)$. No subjects showed an early rise in breath hydrogen, suggesting that small bowel bacterial overgrowth was absent.

The percentage of mannitol recovered in the urine of the Parkinson's disease patients was significantly less than in the controls $(11.72 \%$ $(2.18-20.44)$ vs $16.16 \%(7.0-50.5), \mathrm{p}=0.005)$ (figure 1). Lactulose recovery was similar in the two groups $(0.27 \%(0.03-0.43)$ vs $0.25 \%$ $(0-1.11), p=N S)$. The lactulose: mannitol ratio was significantly higher in the patient group $(0.024(0.007-0.071)$ vs 0.012 $(0.0-0.038), p=0.02)$ (figure 2). There was no correlation between the lactulose:mannitol ratios and weight loss, Hoehn and Yahr score or ADL score for the Parkinson's disease patients. There was no correlation between the percen-

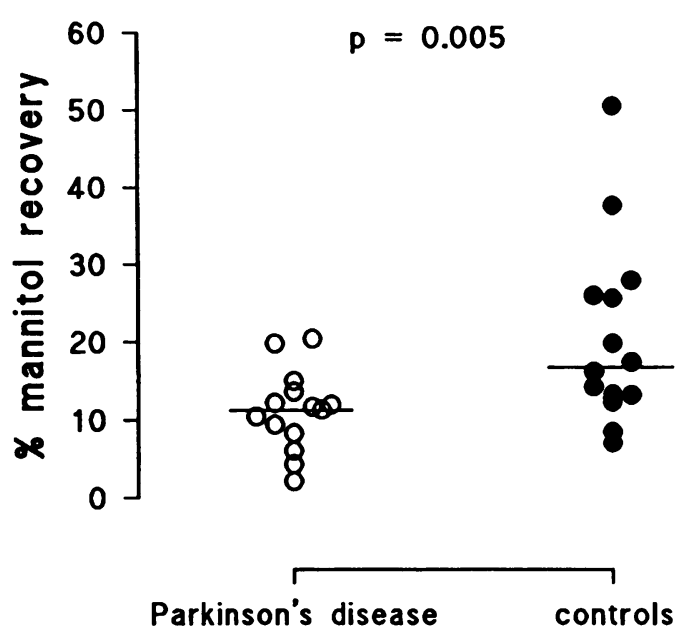

Figure 1 Percentage mannitol recovery in Parkinson disease patients versus control subjects

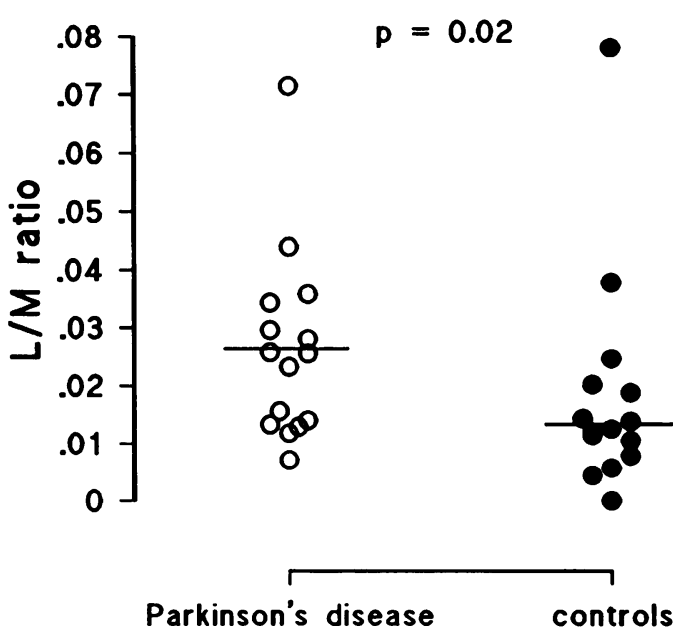

Figure 2 Lactulose/mannitol (L/M) ratio at five hours post-ingestion for patients with Parkinson's disease $(n=15)$ and age/sex matched controls $(n=15)$ 
tage of lactulose or mannitol recovered in the urine and the orocaecal transit time in either group.

\section{Discussion}

In this study of Parkinson's disease patients we have demonstrated two abnormalities of gastrointestinal function by using non-invasive screening tests. Firstly, a significantly prolonged orocaecal transit time was found in patients with Parkinson's disease compared to healthy elderly subjects. The prolongation of the orocaecal transit time was not related to disease severity or duration. The difference between the groups agrees with the findings of Piccione et $a l,{ }^{17}$ who showed that orocaecal transit time does not increase with age alone and is in contrast to those of Haboubi et al, ${ }^{18}$ who suggested age was a significant cause of a prolonged orocaecal transit time. Secondly, we found that there was reduced absorption of mannitol with an increase in the lactulose:mannitol ratio, suggesting there is a reduction in the absorptive surface area of the small intestine. ${ }^{11,12,19} \mathrm{~A}$ number of studies have suggested small bowel bacterial overgrowth may be implicated in malabsorption in elderly subjects, even when the small bowel is anatomically normal, ${ }^{4,5,20}$ while Lipski et al, have suggested small bowel bacterial contamination results from ageing alone. ${ }^{21}$ Sampling of intestinal contents is an invasive technique which is unacceptable to patients, especially those disabled by diseases such as Parkinson's disease. The lactulose hydrogen breath test has been shown to be a good indirect test for small bowel colonisation ${ }^{8}$ and is noninvasive, inexpensive and acceptable to patients. ${ }^{8,20}$ Gastrointestinal hypomotility may be a significant cause ${ }^{7}$ and although we demonstrated prolonged transit times in the Parkinson's disease patients we did not find any evidence of small bowel bacterial contamination. The reason for the prolonged orocaecal transit time is uncertain but may be due to disordered gastrointestinal autonomic function. ${ }^{22,23}$ Oesophageal dysmotility ${ }^{22}$ and prolongation of the colonic transit time ${ }^{23}$ have been demonstrated in Parkinson's disease. Age alone is not responsible for these changes. ${ }^{24}$ Lewy body lesions, the pathognomonic lesion of Parkinson's disease, have been identified in the ganglia of the sympathetic vertebral chain and in the ganglion coeliacum of patients with Parkinson's disease. ${ }^{25,26}$ Therefore autonomic or enteric ${ }^{27}$ nervous system dysfunction may be responsible for the prolongation of the orocaecal transit time.

The differential sugar absorption test is a non-invasive technique for investigating intes-

\section{Methods of measuring transit time}

- hydrogen breath test

- scintigraphy

- radio-opaque markers

- salazopyrine ingestion tinal permeability. It has been used to investigate a number of conditions, particularly coeliac disease. ${ }^{10-12,28,29}$ The reliability of the test has been demonstrated and it is a useful screening test prior to proceeding with more invasive investigations. ${ }^{12,30}$ In normal subjects monosaccharides such as mannitol are absorbed by non-mediated diffusion through small channels in the enterocyte brush border membrane. Disaccharides such as lactulose are excluded from these channels and are absorbed to a lesser extent, either across tight junctions between adjacent enterocytes or through extrusion zones at the tips of the villi. ${ }^{30,31}$ In elderly subjects the excretion of both sugars is reduced but the ratio of the sugars is not significantly different to young subjects and the test remains reliable in older subjects. ${ }^{32}$ The reduced absorption of monosaccharides is postulated to be due to a loss of absorptive surface area which is usually due to villous atrophy. The increased absorption of disaccharides is thought to be due to epithelial injury, increased shedding of cells at extrusion zones, or changes in the tight junction permeability. ${ }^{11,29,31}$

We found that the Parkinson's disease patient group showed decreased urinary recovery of mannitol with normal recovery of lactulose. This excludes gross changes in absorptive surface area (eg, villous atrophy) since the urinary recovery of both sugars would be similarly decreased with a normal lactulose:mannitol ratio. Similarly, changes in orocaecal transit time would be expected to affect the absorption of both sugars equally leaving the lactulose:mannitol ratio unaltered. The only explanation for the decreased mannitol recovery observed in this study is a specific alteration in the enterocyte brush border membrane. Several types of enteric disease, ${ }^{33}$ together with enteropathogenic Escherichia coli, ${ }^{34}$ cause atrophy of the brush border microvilli. Similar alterations in Parkinson's disease patients would be expected to decrease mannitol absorption whilst leaving that of lactulose unchanged, and may be one of the factors involved in under nutrition in Parkinson's disease. Alternatively, changes in the fluidity of the brush border membrane could produce similar results. Further investigation is required to confirm and explain these findings. This will require upper gastrointestinal endoscopy and examination of small intestinal biopsies by both light and electron microscopy.

We would like to thank Nicholas Laboratories, Roche Products Ltd, Broadwater Rd, Welwyn Garden City, Hertfordshire, for supporting this study.

\section{Learning points}

- patients with Parkinson's disease often lose weight

- the aetiology has not been fully elucidated

- dietary deficiency and malabsorption should be excluded

- an increase in energy expenditure is a contributory factor 
1 Levi S, Cox M, Lugon M, Hodkinson M, Tomkins A. Increased energy expenditure in Parkinson's disease. $B M^{\mathfrak{Y}}$ 1990; 301: 1256-7.

2 Markus HS, Cox $M$, Tomkins AM. Raised energy expenditure in Parkinson's disease and its relationship to muscular diture in Parkinson's disease and its re

3 Yapa RSS, Playfer JR, Lye M. Anthropometric and nutritional assessment of elderly patients with Parkinson's disease. F Clin Exp Gerontol 1989; 11: 155-64.

4 McEvoy A, Dutton J, James OFW. Bacterial contamination of the small intestine is an important cause of malabsorption in the elderly. $B M \mathcal{F}$ 1983; 287: 789-93.

5 Montgomery RD, Haboubi NY, Mike NH, Chesner IM, Asquith IP. Causes of malabsorption in the elderly. $A g$ Ageing 1986; 15: 235-40.

6 Davies KN, King D, Davies H. A study of the nutritiona status of elderly patients with Parkinson's disease. Age Ageing 1994; 23: 142-5.

7 Metz G, Drasar BS, Gassull MA, Jenkins DJA, Blendis LM Breath hydrogen test for small bowel bacterial colonisation. Lancet 1976; i: 668-9.

8 Rhodes JM, Middleton P, Jewell DP. The lactulose hydrogen breath test as a diagnostic test for small bowel bacterial overgrowth. Scand f Gastroenterol 1979; 14: 333-6.

9 Tobin MV. Hydrogen breath tests in gastroenterology. Gastroenterology 1987; 22-3.

10 Cobden I, Dickinson RJ, Rothwell J, Axon ATR. Intestina permeability assessed by excretion ratios of two molecules in coeliac disease. $B M \mathcal{F}$ 1978; ii: 1060-1.

11 Menzies IS, Laker MF, Pounder R, et al. Abnormal intestinal permeability to sugars in villous atrophy. Lancet 1979; ii: 1107-9.

12 Juby LJ, Rothwell J, Axon ATR. Cellobiose/mannitol sugar test: a sensitive tubeless test for coeliac disease: results on 1010 unselected patients. Gut 1989; 30: 476-80.

13 Hoehn MM, Yahr MD. Parkinsonism: onset, progression and mortality. Neurology 1967; 17: 427-42.

14 Barer DB. Use of the Nottingham ADL scale in stroke: relationship between functional recovery and length of stay relationship between functional recovery and length of stay

15 Laker MN, Mount JN. Mannitol estimation in biological fluids by gas liquid chromatography of trimethylsily derivatives. Clin Chem 1980; 26: 441-3.

16 Northop CA, Lunn PG, Behrens RH. Automated enzymati assays for the determination of intestinal permeability probes in urine: lactulose and lactose. Clin Chim Acta 1990, 187: $79-88$.

17 Piccione PR, Holt PR, Culpepper-Morgan JA, et al. Intestinal dysmotility syndromes in the elderly: measurement of tinal dysmo

orocaecal transit time. Am $f$ Gastroenterol 1990; 85: 161-4 intestinal transit time in the elderly. Lancet 1988; i: 933.
19 Juby LJ, Rothwell J, Axon ATR. Lactulose/mannitol test: an ideal screen for coeliac disease. Gastroenterology 1989; 96: $79-85$.

20 Haboubi NY, Montgomery RD. Small bowel overgrowth in elderly people. Clinical significance and response to treatment. Age Ageing 1992; 21: 13-9.

21 Lipski PS, Kelly PJ, James OFW. Bacterial contamination of the small bowel in elderly people: is it necessarily pathological? Age Ageing 1992; 21: 5-12.

22 Gibberd FB, Gleeson JA, Gossage AAR, Wilson RSE Oesophageal dilatation in Parkinson's disease. $f$ Neuro Neurosurg Psychiatry 1974; 37: 938-40.

23 Jost WH, Schimrigk K. Constipation in Parkinson's Disease. Klin Wochenschr 1991; 69: 906-9.

24 Melkersson $M$, Andersson $H$, Bosaeus I, Falkheden $T$. Intestinal transit time in constipated and non-constipated geriatric patients. Scand 7 Gastroenterol 1983; 18: 593-7.

25 Den Hartog Jager WA Bethlem J. The distribution of Lewy bodies in the central and autonomic nervous system in idiopathic paralysis agitans. $¥$ Neurol Neurosurg Psychiatry 1960; 23: 283-90.

26 Ohama E, Ikuta F. Parkinson's disease: distribution of Lewy bodies and monoamine neuron system. Acta Neuropathol 1976; 34: $311-9$.

27 Bozeman T, Anuras S. Gastrointestinal motility disturbance in Parkinson's disease. F Gastromotility 1991; 3: 174(A).

28 Harris CE, Griffiths RD, Freestone N, Billingston D, Atherton ST, Macmillan RR. Intestinal permeability in the critically ill. Intensive Care Med 1992; 18: 38-41.

29 Dalzell AM, Freestone NS, Billington D, Heaf DP. Smal intestinal permeability and orocaecal transit time in cystic fibrosis. Arch Dis Child 1990; 65: 585-8.

30 Martines D, Morris AI, Gilmore IT, et al. Comparison between the cellobiose/mannitol and ${ }^{51} \mathrm{Cr}$-labelled ethylenediaminetretrea-acetate absorption tests in the detection of coeliac disease. Clin Sci 1988; 75: 375-8.

31 Hamilton I, Rothwell J, Archer D, Axon ATR. Permeability of the rat small intestine to carbohydrate probe molecules. of the rat small intestine to
Clin Sci 1987; 73: 189-96.

32 Saweirs WM, Andrews DJ, Low-Beer TS. The double sugar test of intestinal permeability in the elderly. Age Ageing 1985; 14: 312-5.

33 Borg M, Phillips AD, Smith MW, Brown D. Enteric disease in early childhood inhibits microvillus expression by potential stem cells. Clin Sci 1993; 84: 377-9.

34 Knutton S, Baldwin T, Williams P. Manjarrez-Hernandez A, Aitken A. The attaching and effacing virulence property of enteropathogenic Escherichia coli. Int 7 Med Microbiol Virol Parasitol Infect Dis 1993; 278: 209-17. 